\title{
COMPOSTOS ANTIOXIDANTES E SUA IMPORTÂNCIA NOS ORGANISMOS
}

\author{
NOVAES, G. M. ${ }^{1}$ \\ SILVA, M. J. D ${ }^{2}$; \\ ACHKAR, M. T. \\ VILEGAS, $\mathrm{W}^{4}$
}

Recebido em: 30/10/2013 - Aprovado em: 15/10/2013 - Disponibilizado em: 15/01/2014

\begin{abstract}
Resumo: A grande quantidade de fatores externos que podem propiciar o aparecimento de radicais livres nos organismos tem criado uma necessidade eminente de entendimento e investimento em tecnologias que possibilitem a procura e extração de compostos antioxidantes de fontes naturais. Estes compostos tem grande potencial de sequestro dos radicais livres que são altamente prejudiciais aos organismos, sendo os principais responsáveis pela diminuição da vida útil dos alimentos, envelhecimento. Estes radicais livres também estão relacionados com doenças como AIDS, artrite, diabetes, doenças do coração etc. Frutas e vegetais são verdadeiras minas de compostos com potencial antioxidante, suas vitaminas e compostos fenólicos apresentam papel essencial na nutrição dos seres vivos, atuando por exemplo como defesa contra degradação de lipídeos e proteínas, evidenciando a importância de uma alimentação rica nesses nutrientes, já que parte das defesas antioxidantes dos organismos provem da dieta. Com esse estudo de revisão pretende-se evidenciar o papel indispensável dos antioxidantes na sobrevivência dos organismos.
\end{abstract}

Palavras-chave: Antioxidante. Radicais livres. Compostos fenólicos.

\begin{abstract}
A large amount of external factors that can foster the emergence of free radicals in organisms has created a imminent need for understanding and technologies that enables the search of antioxidant componds and extraction of antioxidants from natural sources. These compounds have great potential for kidnapping free radicals which are highly harmful to organisms, being the principal responsible for the decrease in the shelf life of foods, and aging. These free radicals are also related to diseases such as AIDS, arthritis, diabetes, heart disease and others. Fruits and vegetables are true mines of compounds with antioxidant potential, its vitamins and phenolic compounds present an essential role in the nutrition of living beings acting as a defense against degradation of lipids and proteins, which indicates the importance of a diet rich in these nutrients, given that part of the antioxidant defenses of the body comes from the diet. This revision study aims to put in evidence the indispensable role of antioxidants in the survival of organisms.
\end{abstract}

keywords: Antioxidant. Radicals. Phenolic compounds.

\footnotetext{
${ }^{1}$ Gabriela Machado Novaes, Ciências Biológicas - UNESP Campus do Litoral Paulista. E-mail:gabriela.mnovaes@gmail.com

${ }^{2}$ Marcelo José Dias Silva, Ciências Farmaceuticas- UNESP Campus do Litoral Paulista. E-mail: marcelo_farma05@yahool.com.br

${ }^{3}$ Marina Teixeira Achkar, Ciências Biológicas - UNESP Campus do Litoral Paulista. E-mail:marina_ta2@hotmail.com

${ }^{4}$ Wagner Vilegas, Prof. Titular em Química Orgânica - UNESP Campus do Litoral Paulista. E-mail: vilegasw@gmail.com 


\section{Introdução}

Os mecanismos de oxidação concentram grandes esforços de pesquisa e de indústrias farmacêuticas, pois os processos de oxidação são a principal causa da diminuição da vida útil de alimentos e matérias-primas no geral, e também por serem os grandes responsáveis pelo envelhecimento dos organismos vivos. Substancias oxidantes podem ser formadas no citoplasma, na membrana celular e mitocôndria e o seu alvo no organismo pode ser o DNA, proteínas, carboidratos e lipídios, sendo este alvo relacionado com o seu sítio de formação (ANDERSON, 1996; YU \& ANDERSON, 1997). Entre as substancias com atividade antioxidante estão os compostos fenólicos, que são capazes de absorver e neutralizar radicais livres e podem ser naturais, ou sintéticos.

A salubridade de muitos antioxidantes vem sendo questionada, tendo em vista o favorecimento de efeitos mutagênicos e carcinogênicos (BIRCH et al., 2001), e a partir dos anos 80 a busca por antioxidantes naturais aumentou consideravelmente, já que os sintéticos tem sido também restringidos por causarem outros males como aumento do peso do fígado e proliferação do retículo endoplasmático (MELO \& GUERRA, 2002; SIMÃO, 1985; YILDRIM, MAVI \& KARA, 2002; ZHENG \& WANG, 2001). Entretanto, em produtos naturais como vegetais e frutas, grande parte dos fitoquímicos e compostos fenólicos estão associados a baixa ocorrência de câncer em humanos, e estudos mostram que o consumo de alimentos com ação antioxidante é capaz de produzir uma ação efetiva contra processos oxidativos naturais dos organismo. Doenças como AIDS, câncer, diabetes, artrite, doenças do coração e malária podem estar ligadas a danos causados por substancias reativas oxigenadas (ROS), que são as várias formas de oxigênio ativado incluindo os radicais livres, que podem ser constituídas nos organismos de várias maneiras, por exemplo através de fontes exógenas como fumaça do tabaco, solventes orgânicos, pesticidas e radiações ionizantes (BRENNA \& PAGLIARINI, 2001; YILDRIM, MAVI \& KARA, 2002) e os danos causados no DNA estão ligados aos processos de mutagênese e carcinogênese .

\section{Defesa antioxidante nos organismos}

O oxigênio é um agente com grande capacidade oxidante, ou seja, é um aceptor de elétrons pois possui dois elétrons não pareados, esta molécula em contato com os compostos orgânicos do sangue causaria danos por oxidação imediatamente caso não houvessem mecanismos de defesa antioxidante nos organismos (BARRY HALLWEL, 1985).

Tendo em vista a toxicidade do $\mathrm{O}_{2}$ sabe-se que os seres aeróbicos apresentam tais defesas antioxidantes e por isso são capazes 
de viver em contato com $\mathrm{O}_{2}$. Provavelmente uma adaptação em organismos multicelulares foi usar baixos níveis de $\mathrm{O}_{2}$ intracorporal, especialmente intramitocondrial, ou seja, as concentrações de $\mathrm{O}_{2}$ interna são muito menores que as do meio ambiente, e isso possivelmente tende a diminuir danos oxidativos in vivo.

As defesas antioxidantes abrangem agentes catalizadores que removem radicais livres e outras substancias radioativas (como as enzimas superóxido dismutase, catalase, peroxidase e 'antioxidantes thiol-específico'); proteínas que minimizam a disponibilidade de pró-oxidantes como íons de ferro e cobre; proteínas que protegem as biomoléculas contra danos, inclusive os oxidativos; moléculas de baixo peso que eliminam os ROS e RNS (substancias reativas nitrogenadas); e existe também a relação entre defesa antioxidantes e a alimentação.

A composisão dessas defesas antioxidantes em um organismo diferem de acordo com o tipo de célula e tecido, mas sabe-se que estas defesas não protegem o organismo completamente, pois estes ainda sofrem danos oxidativos no DNA, proteínas, lipídios e pequenas moléculas quando em contato com $\mathrm{O}_{2}$, e além disso, sabe-se que não há um antioxidante mais eficaz dentre todos os outros, pois nenhuma substancia conhecida até hoje é capaz de atuar de todas as formas contra esse tipo de dano (BARRY HALLLWELL \& JOHN M. C. GUTTERIDGE, 1985).
Quando organismos vivos entram em contato com ROS e RNS muitas dessas defesas antioxidantes entram em ação dependendo de qual e onde esse ROS/RNS foi gerado, portanto, pode-se dizer que qualquer substância que em baixa concentração que consiga atuar de forma a diminuir ou atrasar os danos causados são substancias antioxidantes.

\section{Compostos fenólicos como antioxidantes}

Os radicais livres são controlados no corpo por diversos fatores antioxidantes, e estes podem ser endógenos como as enzimas e proteínas citadas acima, ou exógenos como os provenientes da dieta (CLEYTON MARCOS DE M. SOUSA; et al., 2006). Os compostos fenólicos são os mais frequentemente encontrados em vegetais, podem ser ácidos, simples, taninos, entre outros, estes compostos tem recebido grande investimento pois inibem a peroxidação lipídica. Essa capacidade antioxidante deve-se a estruturas moleculares redutoras que sequestram ou neutralizam os radicais livres, e atuam também na quelação de metais de transição, formando intermediários relativamente estáveis (Naczk, M.; Shahidi, 2004). Nos alimentos a oxidação lipídica é evitada através do uso de sequestradores de radicais livres, como o butil-hidroxi-anisol (BHA), butil-hidroxi-tolueno (BHT). Embora estes compostos possam diminuir os danos, eles não protegem todas as células contra os processos oxidativos e podem inclusive 
apresentar propriedades pró-oxidantes em certas circunstancias (DECKER, 1997).

\section{Antioxidantes na dieta}

As vitaminas antioxidantes são substancias amplamente encontradas nas frutas e vegetais e são capazes de dificultar as reações em cadeia e danos causadas por radicais livres, vitaminas como $\mathrm{A}, \mathrm{E}, \mathrm{C}$, carotenoides, flavonoides entre outros apresentam ações positivas no processo de sequestro de radicais livres, portanto são antioxidante indispensáveis nos organismos vivos. Os níveis de antioxidantes celulares podem sofrer variações quando o organismo entra em contato com fatores oxidantes exógenos como a poluição do ar, tabagismo, e consumo excessivo de álcool, entretanto, estes níveis de defesa podem ser reestabelecidos através do consumo de antioxidantes naturais presentes nos alimentos ou em suplementos vitamínicos.

As vitaminas C, D, A são consumidas em grande quantidade pela população humana e estão presentes em grande diversidade de alimentos. A vitamina $\mathrm{E}$ por exemplo, encontra-se facilmente em lipídeos e diminui os danos causados por radicais livres em casos de doenças específicas, e a vitamina $\mathrm{C}$ é alvo de estudos sobre efeito protetor contra exposição a radiação e medicamentos.

\section{Conclusão}

Existe um balanço delicado entre os compostos oxidantes e os antioxidantes no organismos que são mediados por fatores endógenos ou exógenos. A presença de antioxidantes é indispensável uma vez que os radicais livres que atuam sobre o DNA podem ter ação mutagênica e carcinogênica, e outros radicais que causam danos sobre os lipídeos, proteínas e carboidratos por exemplo podem estar ligados com outras doenças como AIDS, doenças do coração, malária e artrite, e também estão relacionadas com o envelhecimento. Visto a grande capacidade de causar danos irreparáveis sobre os organismos e alimentos, nota-se que a presenta de compostos antioxidantes são indispensáveis e que o entendimento dos mecanismos de oxidação são cruciais para a produção de novos compostos antioxidantes mais eficientes e menos danosos a saúde.

\section{REFERÊNCIAS}

HALLIWELL, B.; GUTTERIDGE J. FREE RADICALS IN BIOLOGY \& MEDICINE. 4TH ED, 1995.

BIANCHI M. L. P.; ANTUNES, L. M. G. FREE RADICALS AND THE MAIN DIETARY ANTIOXIDANTS. Rev. Nutr., Campinas, 12(2): 123-130, maio/ago., 1999

SOUSA, C. M. M. et al. FENÓIS TOTAIS E ATIVIDADE ANTIOXIDANTE DE CINCO PLANTAS MEDICINAIS. Quim. Nova, Vol. 30, No. 2, 351-355, 2007. 
SOARES, S. E. Phenolic acids as antioxidants. Rev. Nutr., Campinas, 15(1):7181, jan./abr., 2002

LEE, J. W.; DAVIS, J. M. Future Applications of Antioxidants in Premature Infants. Curr Opin Pediatr. 2011 April.

KIZHAKEKUTTU, T. J.; WIDLANSKY, M. E. Natural Antioxidants and Hypertension: Promise and Challenges. Cardiovasc Ther. 2010 August. 